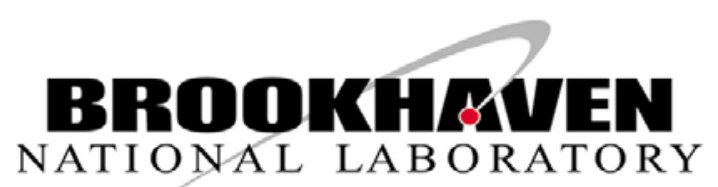

BNL-113433-2017-JA

\title{
Understanding the Degradation Mechanism of Lithium Nickel Oxide Cathodes for Li-Ion Batteries
}

\author{
Jing Xu, Enyuan Hu, Dennis Nordlund, Apurva Mehta, \\ Steven N. Ehrlich, Xiao-Qing Yang, and Wei Tong
}

Submitted to ACS Applied Materials \& Interfaces

January 2017

Chemistry Department

Brookhaven National Laboratory

\author{
U.S. Department of Energy \\ USDOE Office of Science (SC), \\ Basic Energy Sciences (BES) (SC-22)
}

Notice: This manuscript has been authored by employees of Brookhaven Science Associates, LLC under Contract No. DE- SC0012704 with the U.S. Department of Energy. The publisher by accepting the manuscript for publication acknowledges that the United States Government retains a non-exclusive, paid-up, irrevocable, world-wide license to publish or reproduce the published form of this manuscript, or allow others to do so, for United States Government purposes. 


\section{DISCLAIMER}

This report was prepared as an account of work sponsored by an agency of the United States Government. Neither the United States Government nor any agency thereof, nor any of their employees, nor any of their contractors, subcontractors, or their employees, makes any warranty, express or implied, or assumes any legal liability or responsibility for the accuracy, completeness, or any third party's use or the results of such use of any information, apparatus, product, or process disclosed, or represents that its use would not infringe privately owned rights. Reference herein to any specific commercial product, process, or service by trade name, trademark, manufacturer, or otherwise, does not necessarily constitute or imply its endorsement, recommendation, or favoring by the United States Government or any agency thereof or its contractors or subcontractors. The views and opinions of authors expressed herein do not necessarily state or reflect those of the United States Government or any agency thereof. 


\title{
Understanding the Degradation Mechanism of Lithium Nickel Oxide Cathodes for Li-lon Batteries
}

\author{
Jing Xu, ${ }^{\dagger}$ Enyuan $\mathrm{Hu},{ }^{\ddagger}$ Dennis Nordlund,, Apurva Mehta,, Steven N. Ehrlich, ${ }^{\S}$ Xiao-Qing Yang, \\ and Wei Tong*, ${ }^{*}$
}

${ }^{\dagger}$ Energy Storage and Distributed Resources Division, Lawrence Berkeley National Laboratory, Berkeley, California 94720, United
States
${ }^{\ddagger}$ Chemistry Division and ${ }^{\S}$ National Synchrotron Light Source II, Brookhaven National Laboratory, Upton, New York 11973, United
States
${ }^{\|}$Stanford Synchrotron Radiation Lightsource, SLAC National Accelerator Laboratory, Menlo Park, California 94025, United States

ABSTRACT: The phase transition, charge compensation, and local chemical environment of $\mathrm{Ni}$ in $\mathrm{LiNiO}_{2}$ were investigated to understand the degradation mechanism. The electrode was subjected to a variety of bulk and surface-sensitive characterization techniques under different charge-discharge cycling conditions. We observed the phase transition from the original hexagonal $\mathrm{H} 1$ phase to another two hexagonal phases $(\mathrm{H} 2$ and $\mathrm{H} 3)$ upon Li deintercalation. Moreover, the gradual loss of H3phase features was revealed during the repeated charges. The reduction in Ni redox activity occurred at both the charge and the discharge states, and it appeared both in the bulk and at the surface over the extended cycles. The degradation of crystal structure significantly contributes to the reduction of $\mathrm{Ni}$ redox activity, which in turn causes the cycling performance decay of $\mathrm{LiNiO}_{2}$.
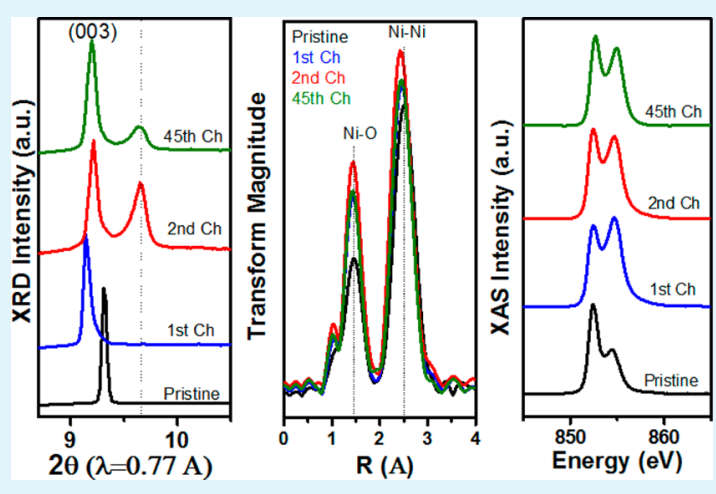

KEYWORDS: Ni-rich layered oxide cathode, capacity fade, phase evolution, redox reaction, surface characteristics, Li-ion batteries

\section{INTRODUCTION}

Rechargeable Li-ion battery technology holds the best promise to serve as power sources for electrical vehicle applications. ${ }^{1}$ Of the few cathode material options, layered lithium transition metal oxides $\left(\mathrm{LiTMO}_{2}\right.$, where TM is a transition metal) are the most promising cathodes for electrical vehicles (EVs) because of their high theoretical capacity $(\sim 270 \mathrm{mAh} / \mathrm{g})$ and relatively high average operating voltage $\left(\sim 3.6 \mathrm{~V} \mathrm{vs} \mathrm{Li}^{+} / \mathrm{Li}\right) .{ }^{2}$ Continuous searches for better cathodes with higher energy and power density, as well as long cycle life, good safety characteristics, and lower cost, has led to some promising materials, e.g., $\mathrm{LiNi}_{1-x-y} \mathrm{Mn}_{x} \mathrm{Co}_{y} \mathrm{O}_{2}(0<x, y<1)(\mathrm{NMC})$ and $\mathrm{Li}-$ $\mathrm{Ni}_{0.8} \mathrm{Co}_{0.15} \mathrm{Al}_{0.05} \mathrm{O}_{2}$ (NCA). ${ }^{3,4}$

Recently, there is an emerging research interest in achieving even-higher practical capacity by developing Ni-rich layered oxides and charging NMC electrodes to even-higher voltage. ${ }^{5-8}$ However, a higher Ni content usually increases the tendency to both surface and bulk phase transformations, particularly at a high state-of-charge or elevated temperature. For example, the highly delithiated $\mathrm{Li}_{x} \mathrm{Ni}_{0.8} \mathrm{Co}_{0.15} \mathrm{Al}_{0.05} \mathrm{O}_{2}(x<0.15)$ cathode contains a complex core-shell surface that consists of a layered $R \overline{3} m$ core, a spinel $F d \overline{3} m$ shell and a rock-salt $F m \overline{3} m$ structure at the surface. ${ }^{9}$ NMC electrodes also suffer from surface instability, particularly under harsh cycling conditions (e.g., high cutoff voltage, $4.7 \mathrm{~V}) .^{10-16}$ This often results from the reduction of transition metals and crystal structural changes (layered $R \overline{3} m \rightarrow$ rock-salt $F m \overline{3} m$ ) at the surface. It ultimately inhibits the kinetics of $\mathrm{Li}$ diffusion and increases the cell impedance, leading to a practical capacity loss. ${ }^{12,13,17}$ Moreover, such phase transformations also occur when the charged NCA and NMC electrodes are heated. It is initially concomitant with a small amount of oxygen loss followed by an exothermic reaction between oxygen and electrolyte, which further accelerates the decomposition of the cathode and finally facilitates thermal runaway, raising a safety concern. ${ }^{18}$ Higher $\mathrm{Ni}$ content leads to an even lower onset temperature of the phase transformation and more oxygen release. ${ }^{18,19}$

Despite its obvious advantage in capacity, the major concerns that prevent Ni-rich layered oxides from practical use are cyclability and safety due to surface decomposition and oxygen release, which become more severe at high states-ofcharge. $^{20-27}$ For NMC and NCA compounds, the presence of several transition metals further complicates the chemical environment at the surface due to the different chemical and electrochemical reactivity of these transition metals, which lead to undesired phase separation and side reactions with the electrolyte. ${ }^{28,29}$ Use of $\mathrm{LiNiO}_{2}$, an end member of Ni-rich NMCs and NCA, is of great importance to deconvolute the 

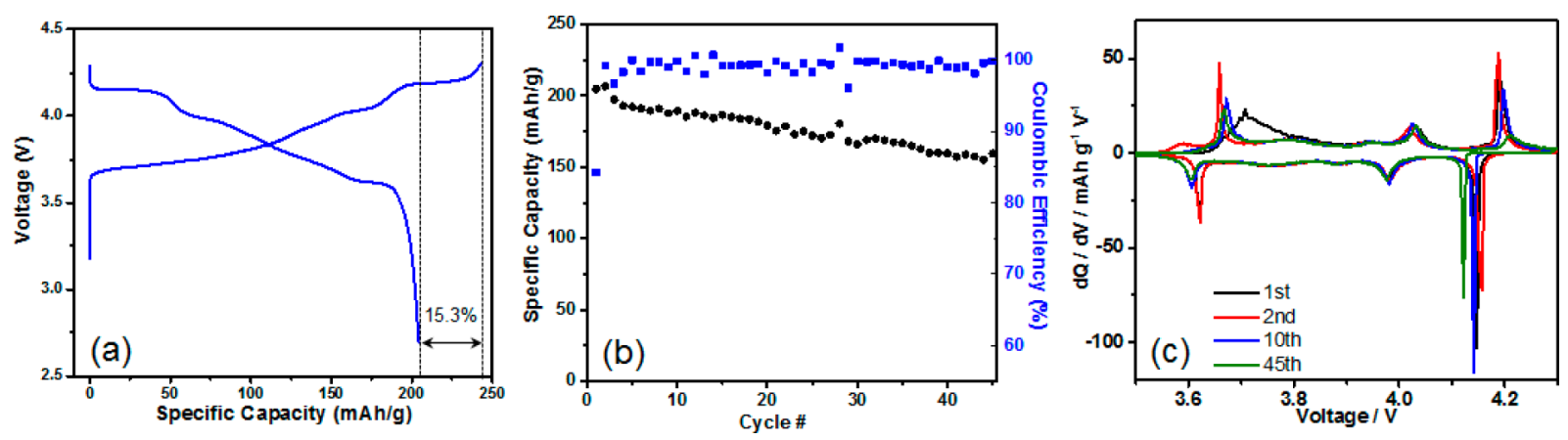

Figure 1. (a) The 1st cycle voltage profiles, (b) cycling performance, and (c) dq/dV plots of $\mathrm{LiNiO}_{2}$. Cells were cycled between 4.3 and $2.7 \mathrm{~V}$ (C/10 for cycles $1-2$ and $\mathrm{C} / 3$ for the subsequent cycles). Capacity at $1 \mathrm{C}$ was defined as $180 \mathrm{mAh} / \mathrm{g}$.

effect of multiple transition metals in NMCs and NCA on the surface and interface properties. Therefore, we investigate $\mathrm{LiNiO}_{2}$ as a model system to reveal the intrinsic performance degradation mechanism originating from high $\mathrm{Ni}$ content for those complex $R \overline{3} m$ layered oxides. Previous X-ray diffraction (XRD) studies on $\mathrm{LiNiO}_{2}$ have revealed the phase transformations from the original hexagonal phase $(\mathrm{H} 1)$ to a second hexagonal $(\mathrm{H} 2)$ and then to a third hexagonal phase $(\mathrm{H} 3)$ during the deintercalation process. ${ }^{30-37}$ A similar phase transformation and coexistence of two hexagonal phases were also observed at a moderate cutoff voltage $(4.4 \mathrm{~V})$ for Ni-rich NMCs and NCA, ${ }^{38,39}$ and $\mathrm{H} 3$-phase formation occurred when they were charged to higher voltage. ${ }^{40,41}$ In addition, the H2-to$\mathrm{H} 3$ phase transformation in $\mathrm{LiNiO}_{2}$ is accompanied by anisotropic lattice changes along the $a$ - and $c$-axes, resulting in a large volume change (9\%) and inducing microcracks in the

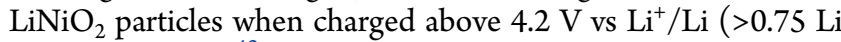
deintercalation). ${ }^{42}$ X-ray absorption spectroscopy (XAS) studies on $\mathrm{LiNiO}_{2}$ electrode at various states-of-charge have shown: (i) a Jahn-Teller distortion for $\mathrm{Ni}^{3+}$, (ii) electrochemical oxidation of $\mathrm{Ni}^{3+}$, and (iii) an undistorted environment for $\mathrm{Ni}^{4+}$. ${ }^{4-46}$ Recently, we found that the surface characteristics of the as-synthesized $\mathrm{LiNiO}_{2}$ (e.g., NiO-like rock-salt species) played a crucial role in the electrochemical performance. ${ }^{47}$ However, the majority of the previous work focused on the first cycle behavior of $\mathrm{LiNiO}_{2}$, and few of them tracked the material properties, particularly at the surface, during extended cycling. Therefore, the fundamental degradation mechanism of $\mathrm{LiNiO}_{2}$ cathode needs to be further investigated.

In this work, we report a detailed study on $\mathrm{LiNiO}_{2}$ after different terms of cycling. The phase evolution, charge compensation, and local chemical environment in the bulk and at the surface are characterized as a function of cycle number. These factors simultaneously contribute to the performance decay. This understanding will not only clarify the aging mechanism of $\mathrm{LiNiO}_{2}$ but also shed light on the optimization strategy for Ni-rich layered oxide cathodes in the next generation of Li-ion batteries.

\section{EXPERIMENTAL SECTION}

$\mathrm{LiNiO}_{2}$ was prepared by ball-milling $\mathrm{Li}_{2} \mathrm{CO}_{3}$ (Sigma-Aldrich) and $\mathrm{Ni}(\mathrm{OH})_{2}$ (Sigma-Aldrich) at $500 \mathrm{rpm}$ for $12 \mathrm{~h}$ (Retsch, PM100) and then annealing at $750{ }^{\circ} \mathrm{C}$ for $12 \mathrm{~h}$ under $\mathrm{O}_{2}$ flow. An extra $10 \mathrm{~mol} \% \mathrm{Li}$ precursor was used to obtain close to stoichiometric $\mathrm{LiNiO}_{2}$.

Electrodes were prepared from slurries containing $80 \mathrm{wt} \% \mathrm{LiNiO}_{2}$ active material, $10 \mathrm{wt} \%$ polyvinylidene fluoride (PVdF), and $10 \mathrm{wt} \%$ acetylene carbon black (Denka, 50\% compressed) in $\mathrm{N}$-methylpyrrolidone (NMP) solvent. The slurries were cast on carbon-coated aluminum current collectors (Exopack Advanced Coatings) using a doctor blade with the height set to $75 \mu \mathrm{m}$ and then dried under vacuum at $120{ }^{\circ} \mathrm{C}$ overnight to form electrodes. Typical loadings of the active materials were around $2.5 \mathrm{mg} / \mathrm{cm}^{2}$. Coin cells (2032-type) were assembled in an Ar-filled glovebox $\left(\mathrm{H}_{2} \mathrm{O}<0.1 \mathrm{ppm}\right)$ with $\mathrm{Li}$ metal as the negative electrode. A Celgard 2400 separator and $1 \mathrm{M}$ $\mathrm{LiPF}_{6}$ electrolyte solutions in 1:2 w/w ethylene carbonate and diethyl carbonate (Ferro Corporation) were used to fabricate the cells. Galvanostatic discharge and charge were performed on a Maccor 4200 battery cycler between 4.3 and $2.7 \mathrm{~V}$. Capacity at $1 \mathrm{C}$ was defined as $180 \mathrm{mAh} / \mathrm{g}$. After the cycling of the batteries, the cycled electrodes were washed with dimethyl carbonate three times and dried completely. The cycled electrodes were then encapsulated with polyimide tape inside the glovebox to minimize air exposure for all ex situ experiments. Synchrotron X-ray diffraction (SXRD) data were collected at beamline 7-2 at the Stanford Synchrotron Radiation Lightsource (SSRL) using an incident photon energy of $16.1 \mathrm{keV}$ with the 300k Pilatus area detector. Hard XAS data were collected in transmission mode using a (220) monochromator at SSRL beamline 4-1. Higher harmonics in the X-ray beam were reduced by detuning the $\mathrm{Si}$ (220) monochromator. Energy calibration was accomplished by using the first inflection points in the spectra of a Ni reference foil. Xray absorption near edge spectroscopy (XANES) data were analyzed by Sam's Interface for XAS Package or SIXPACK software, with the photoelectron energy origin $E_{0}$ determined by the first inflection point of the absorption edge jump. The soft XAS measurements were carried out on beamline $8-2$ at the SSRL and were conducted on powder samples, which were pressed on Au foil to avoid contamination from the adhesive of the carbon tape. Data were acquired under ultrahighvacuum $\left(10^{-9}\right.$ Torr $)$ conditions in a single load at room temperature using total electron yield (TEY) via the drain current and fluorescence yield (FY) modes via a silicon photodiode.

\section{RESULTS AND DISCUSSION}

$\mathrm{LiNiO}_{2}$ was synthesized by a conventional solid-state method, the details of which were reported in a previous publication. ${ }^{47}$ The as-synthesized $\mathrm{LiNiO}_{2}$ exhibited an initial discharge capacity of $205 \mathrm{mAh} / \mathrm{g}$ with a coulombic efficiency of $84.7 \%$ during the first cycle (Figure 1a). The discharge capacity showed a slight increase in the second cycle, which could be attributed to better electrolyte wetting or less polarization. However, the capacity gradually degraded in subsequent cycles, and only $160 \mathrm{mAh} / \mathrm{g}$ was retained at the end of the 45th cycle, corresponding to $78 \%$ of the first cycle capacity (Figure $1 \mathrm{~b}$ ). $\mathrm{LiNiO}_{2}$ experiences a series of phase transformations from the original hexagonal phase $(\mathrm{H} 1)$ to another hexagonal $(\mathrm{H} 2)$ and, finally, a third hexagonal phase $(\mathrm{H} 3)$ upon continuous $\mathrm{Li}$ removal during the charge process. These phase transformations are typically reflected by several oxidationreduction peaks on the differential capacity curves $(\mathrm{d} q / \mathrm{d} V)$. We observed three distinct oxidation peaks at 3.72, 4.03, and 

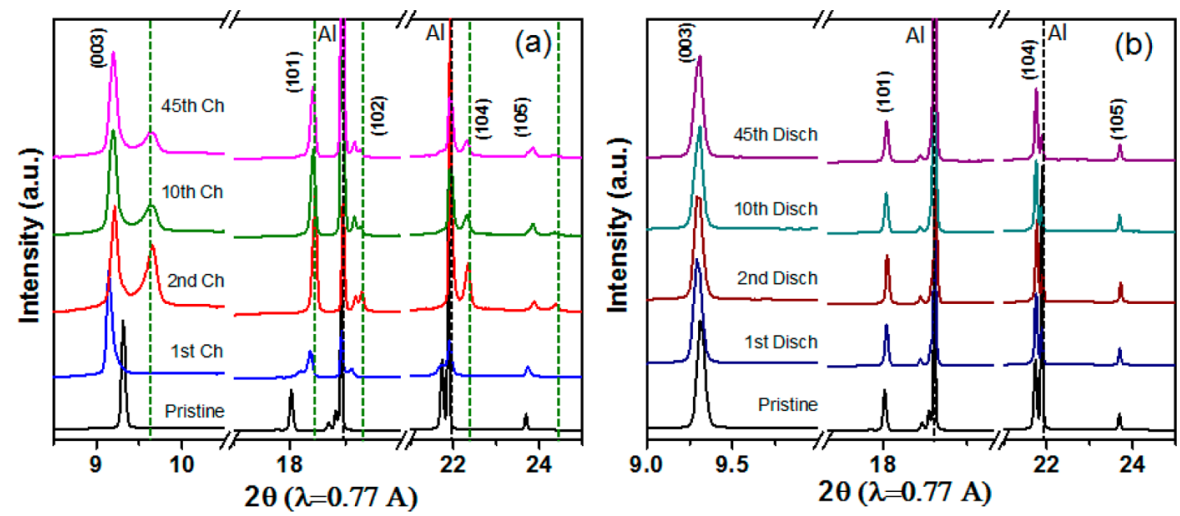

Figure 2. SXRD of $\mathrm{LiNiO}_{2}$ at (a) $4.3 \mathrm{~V}$ charge states and (b) $2.7 \mathrm{~V}$ discharge states for the selected cycles. Diffraction peaks related to Al current collectors and $\mathrm{H} 3$ phases are highlighted by black and green dash lines, respectively.
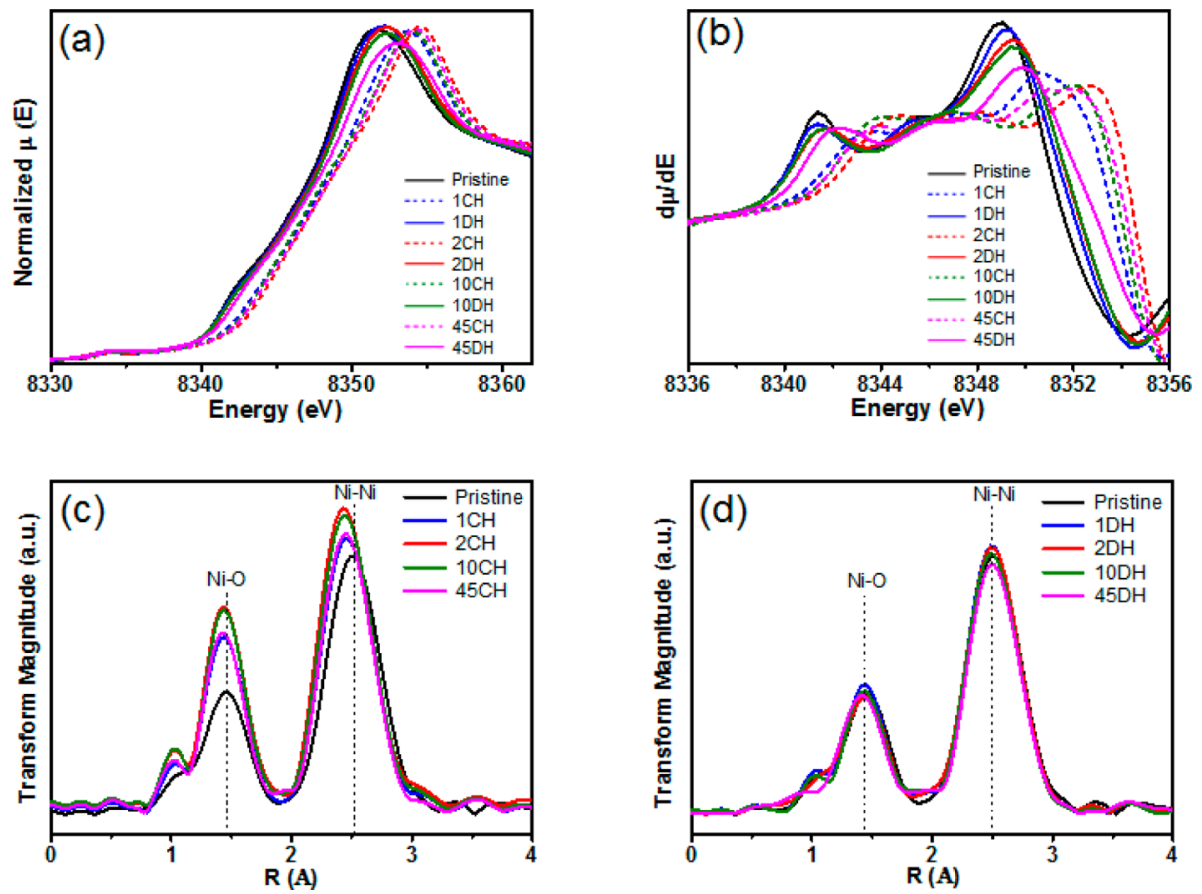

Figure 3. (a) XANES, (b) XANES derivative plots for selected states, and Fourier transform radial distribution function for the Ni K-edge EXAFS at (c) charge and (d) discharge states.

4.19 $\mathrm{V}$ during the first charge and their corresponding reduction peaks around 3.61, 3.98, and $4.15 \mathrm{~V}$ during the first discharge (black curve in Figure 1c). They can be assigned to the phase transformations from $\mathrm{H} 1$ to $\mathrm{H} 2$ and $\mathrm{H} 3$, respectively. ${ }^{36,48}$ After the first cycle, a distinct feature on the $\mathrm{dq} / \mathrm{dV}$ plot was the shift of the oxidation peak at 3.72 to $3.66 \mathrm{~V}$ in the second charge, suggesting a smaller polarization in the second cycle. Our previous studies revealed the presence of $\mathrm{Li}_{2} \mathrm{CO}_{3}$ on the surface of the as-synthesized $\mathrm{LiNiO}_{2}$. This small decrease in cell polarization could be related to the decomposition of $\mathrm{Li}_{2} \mathrm{CO}_{3}$ surface species during the first cycle. Upon extended cycling, the paired oxidation and reduction peaks during the charge-discharge process progressively separated, the extent of which became large, in particular, in the high-voltage region $(\sim 4.2 \mathrm{~V})$. The cell impedance rise over the extended cycles was also evidenced by an irreversible capacity when a lower current, C/10, was applied to the electrode after being cycled at $\mathrm{C} / 3$ for 25 cycles. Additionally, the oxidation peak at $4.18 \mathrm{~V}$, related to $\mathrm{H} 2$-to- $\mathrm{H} 3$ transformation, was significantly reduced from the 10th to 45th cycle, suggesting that the $\mathrm{H} 3$ phase formation was suppressed. This could be attributed to the presence of $\mathrm{Ni}$ ions in $\mathrm{Li}$ layer, preventing Ni slab shifting and Li diffusion. ${ }^{36}$ To test whether the bulk structural change was responsible for the capacity decay, we conducted ex situ SXRD at the end of charge and discharge states for the selected cycles to further investigate the phase evolution of $\mathrm{LiNiO}_{2}$ over the extended cycles.

Ex situ SXRD patterns of the pristine and cycled $\mathrm{LiNiO}_{2}$ electrodes were collected in the transmission mode; thus, the peaks from the $\mathrm{Al}$ current collector are present (black dash lines) in Figure 2. Due to the overlapping of $\mathrm{Al}$ peaks with the (102) and (104) peaks of $\mathrm{LiNiO}_{2}$, our analysis was mainly focused on the most intense (003) diffraction peak with the assistance of other $(h 0 l)$ diffraction peaks, which were sufficient to monitor the lattice changes and investigate the phase evolution. All the SXRD patterns were normalized to the intensity of the most-intense (003) diffraction peak for comparison. $\mathrm{LiNiO}_{2}$ maintained good crystallinity and cation 

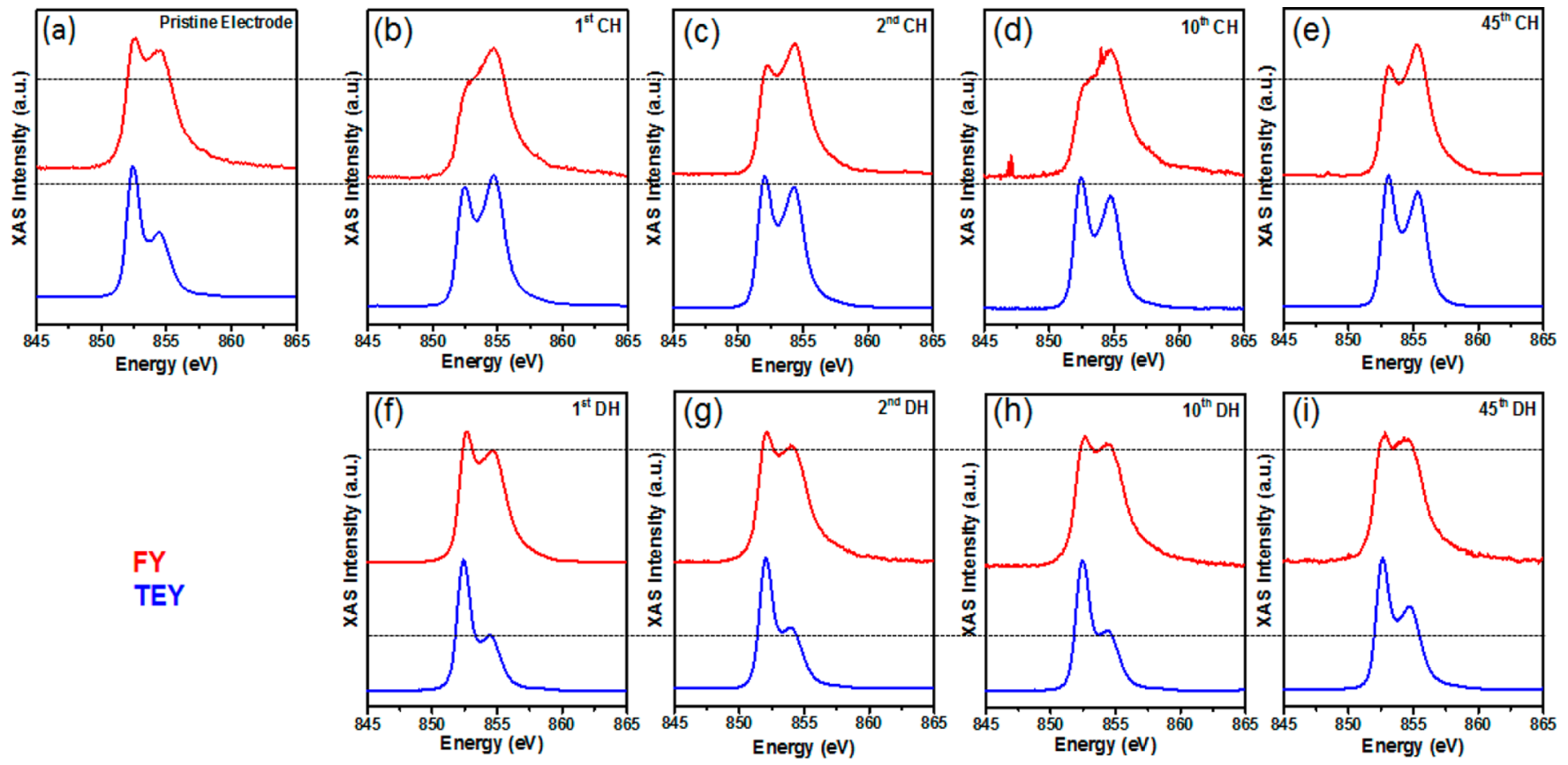

Figure 4. Soft XAS spectra of Ni L3-edge at: (a) pristine state, (b) 1st charge, (c) 2nd charge, (d) 10th charge, (e) 45th charge, (f) 1st discharge, (g) 2nd discharge, (h) 10th discharge, and (i) 45th discharge. The dash lines in the plots provide guidance for comparison of the Ni L3-edge between the 1st cycle and later cycles.

ordering after being formulated into an electrode. After the first charge, the (003) diffraction peak shifted to lower $2 \theta$ values and the $(h 0 l)$ peaks shifted to higher $2 \theta$ values, suggesting the formation of a $\mathrm{H} 2$ phase with a larger $c$ lattice parameter. At the end of the second charge, another set of diffraction peaks (green dash lines) appeared at slightly higher $2 \theta$ values than those associated with the $\mathrm{H} 2$ phase, indicating a contraction of the crystal lattice due to a $\mathrm{H} 3$ phase formation. Afterward, the $\mathrm{H} 3$ phase repeatedly occurred at the end of charge in subsequent cycles (cycle 10 and cycle 45). However, all H3 diffraction peaks became broadened and the intensity decreased remarkably, which is consistent with the significant reduction in the $\mathrm{H} 3$ oxidation peak shown on the $\mathrm{d} q / \mathrm{d} V$ plot (Figure 1c). In addition to the structural change of the charged states, the pristine structure was not completely recovered after the first discharge. As shown in Figure $2 b$, the (003) peak slightly shifted to the lower angle region, compared to its pristine state, suggesting a small lattice expansion along the $c$ direction, likely due to the irreversible structural changes that prevent the fully retaking of the $\mathrm{Li}$ ions. In subsequent cycles, the variations were fairly small, indicated by the similar peak positions and intensities in the SXRD patterns at discharged states.

The phase transformation is strongly related to the $\mathrm{Li}$ content in the cycled $\mathrm{Li}_{x} \mathrm{NiO}_{2}(0<x<1)$ electrode. The whole range was previously divided into four regions: (1) hexagonal $\mathrm{H} 1$ phase for $0<x<0.25$, (2) coexistence region of $\mathrm{H} 1$ and $\mathrm{H} 2$ phases for $0.25<x<0.55$, (3) second hexagonal $\mathrm{H} 2$ phase for $0.55<x<0.75$, and (4) coexisting $\mathrm{H} 2+\mathrm{H} 3$ phase for $0.75<x$ $<1) .^{32}$ It is worth to point out that the Li contents for each region may vary. If we assume the starting $\mathrm{LiNiO}_{2}$ electrode contained $1 \mathrm{~mol} \mathrm{Li}$ per formula unit, about $0.887 \mathrm{Li}$ was extracted from the lattice during the first charge; however, only the $\mathrm{H} 2$-phase formation was revealed. In addition, the oxidation and reduction peaks related to the $\mathrm{H} 3$ phase were observed in the $\mathrm{d} q / \mathrm{d} V$ plot. Previous in situ XRD studies on fully charged $\mathrm{Li}_{x} \mathrm{NiO}_{2}$ electrode showed the $\mathrm{H} 3$-phase formation even for
$0.82 \mathrm{Li}$ removal. ${ }^{30}$ In our case, decomposition of $\mathrm{Li}_{2} \mathrm{CO}_{3}$ surface species could contribute to the first charge capacity and account for the most irreversible capacity at $4.3 \mathrm{~V}$ cutoff. The extracted Li during the first charge was likely around 0.747 (1st cycle reversible $\mathrm{Li}$ ), which was on the edge of the $\mathrm{H} 2+\mathrm{H} 3$ coexistence region $(0.75<x<1)$. During the second charge, the $\mathrm{Li}_{1-x} \mathrm{NiO}_{2}$ electrode with better electrolyte wetting, less polarization, or both resulted in a slightly greater Li extraction (therefore, a stable H3-phase formation). However, the discrepancy in the features related to $\mathrm{H} 3$-phase formation could result from the difference in electrochemical and ex situ SXRD measurements due to the possible relaxation of the $\mathrm{H} 3$ lattice during the ex situ SXRD experiment.

In parallel with the phase evolution tracked by SXRD, hard XAS was also performed at the $\mathrm{Ni}$ K-edge $(8333 \mathrm{eV})$ to elucidate the charge-compensation mechanism and local environments around $\mathrm{Ni}$ ions (Figure 3). In the XANES (Figure 3a), the Ni edge shifted to higher energy after each selected charge state (dash lines) compared to the edge in the pristine electrode (black solid line), owing to the oxidation of $\mathrm{Ni}$ ions during the charge processes. Close examination of the edge positions on the derivative plots in Figure $3 \mathrm{~b}$ revealed the highest $\mathrm{Ni}$ valence state at the end of the second charge (red dashed line), which is in accordance with the most prominent $\mathrm{H} 3$-phase formation (Figure 2a). It further confirmed that more $\mathrm{Li}$ ions were extracted during the second charge than the first charge. At the 10th and 45th cycle, the Ni edge at the charging states slightly moved to lower energy than that at the second charge. The discharge states (solid lines) upon cycling show a different trend in which a continuous shift to higher energy indicates less reduced $\mathrm{Ni}$ after repeated discharges. These two changes lead to the conclusion that the amount of electrons from $\mathrm{Ni}$ redox was getting smaller after cycling, and the decrease in Ni redox change resulted from both the charge and discharge states. 
To understand the local environment of $\mathrm{Ni}$, we analyzed the Fourier-transformed (weighted) Ni K-edge extended X-ray absorption fine structure (EXAFS). In Figure 3c,d, the distinct peaks at 1.4 and $2.4 \AA$ are assigned to the $\mathrm{Ni}-\mathrm{O}$ and $\mathrm{Ni}-\mathrm{Ni}$ interactions of the first and second coordination shells. Both $\mathrm{Ni}-\mathrm{O}$ and $\mathrm{Ni}-\mathrm{Ni}$ peaks shifted to lower $\mathrm{R}$ values after charging compared to those of the pristine state, indicating a contraction in the $\mathrm{Ni}-\mathrm{O}$ and $\mathrm{Ni}-\mathrm{Ni}$ interatomic distances due to the oxidation of $\mathrm{Ni}$ ions. However, the amplitude of these peaks varied at the end of charge for the selected cycles. The small and broad peak in the pristine state is due to the Jahn-Teller active $\mathrm{Ni}^{3+} \cdot{ }^{49,50}$ During the repeated charges, the amplitude of these peaks increased and reached a maximum after the second charge then gradually decreased, suggesting a maximal degree of $\mathrm{Ni}$ oxidation after the second charge and a slight decrease after the charges in the later cycles. As opposed to the charge states, the $\mathrm{Ni}$ local environments were basically recovered after each discharge in the subsequent cycles (Figure $3 \mathrm{~d}$ ). The intensity of $\mathrm{Ni}-\mathrm{O}(1.4 \AA)$ and $\mathrm{Ni}-\mathrm{Ni}(2.4 \AA)$ shells tended to decrease at the 45 th cycle; however, the intensity decrease at the discharged states was very small.

Soft XAS spectra were collected at various cycled states to investigate the variation of surface properties over the extended cycles (Figure 4). A pair of detection modes, total electron yield (TEY) and fluorescence yield (FY), were collected simultaneously on pristine and cycled electrodes. The different mean free paths of electrons and fluorescence photons in the samples enable a typical probing depth of 2-5 and $\sim 50 \mathrm{~nm}$ from the surface toward the bulk for TEY and FY mode, respectively. Valence-state changes for the Ni L-edge can be qualitatively obtained through the deconvolution of the Ni L3-edge into high-energy $\left(\mathrm{L} 3_{\text {high }}\right)$ and low-energy $\left(\mathrm{L} 3_{\text {low }}\right)$ states, where the ratio, $\mathrm{L} 3_{\text {high }} / \mathrm{L} 3_{\text {low }}$, is in a positive relationship with the $\mathrm{Ni}$ valence state. The FY and TEY modes of Ni L3-edge for electrodes at various states shown in Figure 4 are normalized with respect to the $\mathrm{L} 3_{\text {low }}$ feature. In the pristine state (Figure $4 \mathrm{a}$ ), the $\mathrm{L} 3_{\text {high }}$-to- $\mathrm{L} 3_{\text {low }}$ ratio is smaller in TEY mode (blue) than that in FY mode (red), indicating a lower valence state of $\mathrm{Ni}$ ions at the surface compared to that in the bulk of the pristine electrode. After charge processes (Figure $4 \mathrm{~b}-\mathrm{e}$ ), the $\mathrm{L} 3_{\text {high }}$-to-L $3_{\text {low }}$ ratio was systematically increased compared to that of the pristine electrode, owing to the $\mathrm{Ni}$ oxidation, although the Ni valence state at the surface was still lower than that in the bulk, as suggested by a smaller $\mathrm{L} 3_{\text {high }}$-to- $\mathrm{L} 3_{\text {low }}$ ratio in TEY mode. Interestingly, the $\mathrm{L} 3_{\text {high }}$-to- $\mathrm{L} 3_{\text {low }}$ ratios in TEY mode at charged states gradually decreased from the first to 45th cycle, indicating that the degree of $\mathrm{Ni}$ oxidation was reduced at the surface over the extended cycles. After the first discharge, the surface characteristics were similar to that in the pristine state. However, the $\mathrm{L} 3_{\text {high }}$-to- $\mathrm{L} 3_{\text {low }}$ ratio in TEY mode increased after the 10th discharge and further enlarged after the 45th discharge, revealing that the $\mathrm{Ni}$ reduction after the discharge over long-term cycling was not complete, i.e., the $\mathrm{Ni}$ redox reaction was not fully reversible at the surface. The trend of $\mathrm{Ni}$ oxidation change upon charging and discharging in FY mode is not as remarkable as that in TEY mode. This variation in FY mode is likely resulted by the experimental fluctuations due to the intrinsic origin of the fluorescent beam. Variation of $\mathrm{Ni}$ oxidation state in the bulk detected by hard XAS and at the surface by soft XAS showed that reversible Ni redox within each cycle was getting smaller both in the bulk and at the surface. This is direct evidence of the electronic structure changes that underpin the reversible capacity loss.

\section{CONCLUSIONS}

In summary, we investigated the phase evolution, charge compensation that occurred on $\mathrm{Ni}$ in the bulk and at the surface of $\mathrm{LiNiO}_{2}$ over the extended cycles to understand the degradation mechanism. Our ex situ XRD experiments revealed the phase transition from the original hexagonal phase $(\mathrm{H} 1)$ to another two hexagonal phases $(\mathrm{H} 2$ and $\mathrm{H} 3)$ during the deintercalation processes, but the gradual loss of $\mathrm{H} 3$-phase features was revealed after the repeated charges. Moreover, ex situ XANES and EXAFS results showed more reduced Ni after the repeated charges and more oxidized $\mathrm{Ni}$ after the repeated discharges, suggesting a decrease in $\mathrm{Ni}$ redox activity over the extended cycles. Ex situ soft XAS analysis illustrated a similar trend in the $\mathrm{Ni}$ oxidation state change at the surface. Overall, the degradation in the crystal structure and $\mathrm{Ni}$ redox activity in the bulk and at the surface were responsible for the fast capacity fade of $\mathrm{LiNiO}_{2}$. This aging mechanism of $\mathrm{LiNiO}_{2}$ is of great importance in devising an optimization strategy for Ni-rich layered oxide cathodes in the next-generation Li-ion batteries.

\section{AUTHOR INFORMATION}

\section{Corresponding Author}

*E-mail: weitong@lbl.gov.

\section{Author Contributions}

The manuscript was written through contributions of all authors. All authors have given approval to the final version of the manuscript.

\section{Notes}

The authors declare no competing financial interest.

\section{ACKNOWLEDGMENTS}

This work was supported by the Assistant Secretary for Energy Efficiency and Renewable Energy, Office of Vehicle Technologies of the U.S. Department of Energy under contract no. DE-AC02-05CH11231. Synchrotron XRD and soft XAS work was carried out at the Stanford Synchrotron Radiation Lightsource, a Directorate of SLAC National Accelerator Laboratory and an Office of Science User Facility operated for the U.S. Department of Energy Office of Science by Stanford University. Use of the Stanford Synchrotron Radiation Lightsource, SLAC National Accelerator Laboratory, is supported by the U.S. Department of Energy, Office of Science, Office of Basic Energy Sciences under contract no. DEAC02-76SF00515. The work at Brookhaven National Laboratory was supported by the U.S. Department of Energy, the Assistant Secretary for Energy Efficiency and Renewable Energy, Office of Vehicle Technologies under contract no. DE-SC0012704. W.T. greatly appreciates the fruitful discussion with Marca Doeff at Lawrence Berkeley National Laboratory.

\section{REFERENCES}

(1) Etacheri, V.; Marom, R.; Elazari, R.; Salitra, G.; Aurbach, D. Challenges in the Development of Advanced Li-Ion Batteries: a review. Energy Environ. Sci. 2011, 4 (9), 3243-3262.

(2) Whittingham, M. S. Ultimate Limits to Intercalation Reactions for Lithium Batteries. Chem. Rev. 2014, 114 (23), 11414-11443.

(3) Whittingham, M. S. Lithium Batteries and Cathode Materials. Chem. Rev. 2004, 104 (10), 4271-4301.

(4) Nitta, N.; Wu, F.; Lee, J. T.; Yushin, G. Li-Ion Battery Materials: Present and Future. Mater. Today 2015, 18 (5), 252-264.

(5) Choi, M. H.; Yoon, C. S.; Myung, S. T.; Lim, B. B.; Komaba, S.; Sun, Y. K. Effect of Lithium in Transition Metal Layers of Ni-Rich 
Cathode Materials on Electrochemical Properties. J. Electrochem. Soc. 2015, 162 (12), A2313-A2318.

(6) Hwang, B. J.; Tsai, Y. W.; Chen, C. H.; Santhanam, R. Influence of Mn Content on the Morphology and Electrochemical Performance of LiNil-x-yCoxMnyO2 Cathode Materials. J. Mater. Chem. 2003, 13 (8), 1962-1968.

(7) Shi, J.-L.; Zhang, J.-N.; He, M.; Zhang, X.-D.; Yin, Y.-X.; Li, H.; Guo, Y.-G.; Gu, L.; Wan, L.-J. Mitigating Voltage Decay of Li-Rich Cathode Material via Increasing Ni Content for Lithium-Ion Batteries. ACS Appl. Mater. Interfaces 2016, 8 (31), 20138-20146.

(8) Qing, R.-P.; Shi, J.-L.; Xiao, D.-D.; Zhang, X.-D.; Yin, Y.-X.; Zhai, Y.-B.; Gu, L.; Guo, Y.-G. Enhancing the Kinetics of Li-Rich Cathode Materials through the Pinning Effects of Gradient Surface Na+ Doping. Adv. Energy Mater. 2016, 6 (6).10.1002/aenm.201670035

(9) Wu, L.; Nam, K.-W.; Wang, X.; Zhou, Y.; Zheng, J.-C.; Yang, X.Q; Zhu, Y. Structural Origin of Overcharge-Induced Thermal Instability of Ni-Containing Layered-Cathodes for High-EnergyDensity Lithium Batteries. Chem. Mater. 2011, 23 (17), 3953-3960.

(10) Kuriyama, H.; Saruwatari, H.; Satake, H.; Shima, A.; Uesugi, F.; Tanaka, H.; Ushirogouchi, T. Observation of Anisotropic Microstructural Changes during Cycling in LiNi0.5Co0.2Mn0.3O2 Cathode Material. J. Power Sources 2015, 275, 99-105.

(11) Lee, Y. M.; Nam, K. M.; Hwang, E. H.; Kwon, Y. G.; Kang, D. H.; Kim, S. S.; Song, S. W. Interfacial Origin of Performance Improvement and Fade for $4.6 \mathrm{~V}$ LiNi0.5Co0.2Mn0.3O2 Battery Cathodes. J. Phys. Chem. C 2014, 118 (20), 10631-10639.

(12) Lin, F.; Nordlund, D.; Markus, I. M.; Weng, T.-C.; Xin, H. L.; Doeff, M. M. Profiling the Nanoscale Gradient in Stoichiometric Layered Cathode Particles for Lithium-Ion Batteries. Energy Environ. Sci. 2014, 7 (9), 3077-3085.

(13) Lin, F.; Markus, I. M.; Nordlund, D.; Weng, T.-C.; Asta, M. D.; Xin, H. L.; Doeff, M. M. Surface Reconstruction and Chemical Evolution of Stoichiometric Layered Cathode Materials for LithiumIon Batteries. Nat. Commun. 2014, 5, 3529.

(14) Hwang, S.; Kim, S. M.; Bak, S.-M.; Cho, B.-W.; Chung, K. Y.; Lee, J. Y.; Chang, W.; Stach, E. A. Investigating Local Degradation and Thermal Stability of Charged Nickel-Based Cathode Materials through Real-Time Electron Microscopy. ACS Appl. Mater. Interfaces 2014, 6 (17), 15140-15147.

(15) Hwang, S.; Chang, W.; Kim, S. M.; Su, D.; Kim, D. H.; Lee, J. Y.; Chung, K. Y.; Stach, E. A. Investigation of Changes in the Surface Structure of LixNi0.8Co0.15Al0.05O2 Cathode Materials Induced by the Initial Charge. Chem. Mater. 2014, 26 (2), 1084-1092.

(16) Bak, S.-M.; Nam, K.-W.; Chang, W.; Yu, X.; Hu, E.; Hwang, S.; Stach, E. A.; Kim, K.-B.; Chung, K. Y.; Yang, X.-Q. Correlating Structural Changes and Gas Evolution during the Thermal Decomposition of Charged LixNi0.8Co0.15Al0.05O2 Cathode Materials. Chem. Mater. 2013, 25 (3), 337-351.

(17) Noh, H.-J.; Youn, S.; Yoon, C. S.; Sun, Y.-K. Comparison of the Structural and Electrochemical Properties of Layered Li[NixCoyMnz]$\mathrm{O} 2(\mathrm{x}=1 / 3,0.5,0.6,0.7,0.8$ and 0.85$)$ Cathode Material for LithiumIon Batteries. J. Power Sources 2013, 233, 121-130.

(18) Bang, H. J.; Joachin, H.; Yang, H.; Amine, K.; Prakash, J. Contribution of the Structural Changes of $\mathrm{LiNi0} .8 \mathrm{Co} 0.15 \mathrm{Al} 0.05 \mathrm{O} 2$ Cathodes on the Exothermic Reactions in Li-Ion Cells. J. Electrochem. Soc. 2006, 153 (4), A731-A737.

(19) Bak, S. M.; Hu, E. Y.; Zhou, Y. N.; Yu, X. Q.; Senanayake, S. D.; Cho, S. J.; Kim, K. B.; Chung, K. Y.; Yang, X. Q.; Nam, K. W. Structural Changes and Thermal Stability of Charged LiNixMnyCozO2 Cathode Materials Studied by Combined In Situ Time-Resolved XRD and Mass Spectroscopy. ACS Appl. Mater. Interfaces 2014, 6 (24), 22594-22601.

(20) Eom, J.; Kim, M. G.; Cho, J. Storage Characteristics of LiNi0.8Co0.1 + x Mn0.1 - x O2 ( $\mathrm{x}=0,0.03$, and 0.06) Cathode Materials for Lithium Batteries. J. Electrochem. Soc. 2008, 155 (3), A239-A245.

(21) Muto, S.; Sasano, Y.; Tatsumi, K.; Sasaki, T.; Horibuchi, K.; Takeuchi, Y.; Ukyo, Y. Capacity-Fading Mechanisms of LiNiO2-Based
Lithium-Ion Batteries: II. Diagnostic Analysis by Electron Microscopy and Spectroscopy. J. Electrochem. Soc. 2009, 156 (5), A371-A377.

(22) Sasaki, T.; Nonaka, T.; Oka, H.; Okuda, C.; Itou, Y.; Kondo, Y.; Takeuchi, Y.; Ukyo, Y.; Tatsumi, K.; Muto, S. Capacity-Fading Mechanisms of LiNiO2-Based Lithium-Ion Batteries: I. Analysis by Electrochemical and Spectroscopic Examination. J. Electrochem. Soc. 2009, 156 (4), A289-A293.

(23) Muto, S.; Tatsumi, K.; Sasaki, T.; Kondo, H.; Ohsuna, T.; Horibuchi, K.; Takeuchi, Y. Mapping of Heterogeneous Chemical States of Lithium in a LiNiO2-Based Active Material by Electron Energy-Loss Spectroscopy. Electrochem. Solid-State Lett. 2010, 13 (8), A115-A117.

(24) Kojima, Y.; Muto, S.; Tatsumi, K.; Kondo, H.; Oka, H.; Horibuchi, K.; Ukyo, Y. Degradation Analysis of a Ni-Based Layered Positive-Electrode Active Material Cycled at elevated temperatures studied by scanning transmission electron microscopy and electron Energy-Loss Spectroscopy. J. Power Sources 2011, 196 (18), 77217727.

(25) Konishi, H.; Yoshikawa, M.; Hirano, T. The Effect of Thermal Stability for High-Ni-Content Layer-Structured Cathode Materials, LiNi0.8Mn0.1-xCo0.1MoxO2 $(\mathrm{x}=0,0.02,0.04)$. J. Power Sources 2013, 244, 23-28.

(26) Xiong, X.; Wang, Z.; Yue, P.; Guo, H.; Wu, F.; Wang, J.; Li, X. Washing Effects on Electrochemical Performance and Storage Characteristics of LiNi0.8Co0.1Mn0.1O2 as Cathode Material for Lithium-Ion Batteries. J. Power Sources 2013, 222, 318-325.

(27) Jung, S.-K.; Gwon, H.; Hong, J.; Park, K.-Y.; Seo, D.-H.; Kim, H.; Hyun, J.; Yang, W.; Kang, K. Understanding the Degradation Mechanisms of LiNi0.5Co0.2Mn0.3O2 Cathode Material in Lithium Ion Batteries. Adv. Energy Mater. 2014, 4 (1).130078710.1002/ aenm.201300787

(28) Zheng, J. M.; Kan, W. H.; Manthiram, A. Role of Mn Content on the Electrochemical Properties of Nickel-Rich Layered LiNi0.8$\mathrm{xCo} 0.1 \mathrm{Mn} 0.1+\mathrm{xO} 2(0.0 \leq x \leq 0.08)$ Cathodes for Lithium-Ion Batteries. ACS Appl. Mater. Interfaces 2015, 7 (12), 6926-6934.

(29) Yan, P. F.; Zheng, J. M.; Lv, D. P.; Wei, Y.; Zheng, J. X.; Wang, Z. G.; Kuppan, S.; Yu, J. G.; Luo, L. L.; Edwards, D.; Olszta, M.; Amine, K.; Liu, J.; Xiao, J.; Pan, F.; Chen, G. Y.; Zhang, J. G.; Wang, C. M. Atomic-Resolution Visualization of Distinctive Chemical Mixing Behavior of $\mathrm{Ni}, \mathrm{Co}$, and $\mathrm{Mn}$ with $\mathrm{Li}$ in Layered Lithium TransitionMetal Oxide Cathode Materials. Chem. Mater. 2015, 27 (15), 53935401.

(30) Li, W.; Reimers, J. N.; Dahn, J. R. In-Situ X-ray-Diffraction and Electrochemical Studies of Li1-xNiO2. Solid State Ionics 1993, 67 (12), 123-130.

(31) Dokko, K.; Nishizawa, M.; Horikoshi, S.; Itoh, T.; Mohamedi, M.; Uchida, I. In Situ Observation of LiNiO2 Single-Particle Fracture during Li-Ion Extraction and Insertion. Electrochem. Solid State Lett. 2000, 3 (3), 125-127.

(32) Yang, X. Q.; Sun, X.; McBreen, J. New Findings on the Phase Transitions in Lil-xNiO2: In Situ Synchrotron X-ray Diffraction Studies. Electrochem. Commun. 1999, 1 (6), 227-232.

(33) Guilmard, M.; Croguennec, L.; Denux, D.; Delmas, C. Thermal Stability of Lithium Nickel Oxide Derivatives. Part I: LixNi1.02O2 and LixNi0.89Al0.16O2 ( $\mathrm{x}=0.50$ and 0.30). Chem. Mater. 2003, 15 (23), 4476-4483.

(34) Delmas, C.; Ménétrier, M.; Croguennec, L.; Levasseur, S.; Pérès, J. P.; Pouillerie, C.; Prado, G.; Fournès, L.; Weill, F. Lithium Batteries: a New Tool in Solid State Chemistry. Int. J. Inorg. Mater. 1999, 1 (1), $11-19$.

(35) Arai, H.; Okada, S.; Ohtsuka, H.; Ichimura, M.; Yamaki, J. Characterization and Cathode Performance of $\mathrm{Li} 1-\mathrm{xNi} 1+\mathrm{xO} 2$ Prepared with the Excess Lithium Method. Solid State Ionics 1995, 80 (3-4), 261-269.

(36) Ohzuku, T.; Ueda, A.; Nagayama, M. Electrochemistry and Structural Chemistry of $\mathrm{LiNiO} 2(\mathrm{R} \overline{3} \mathrm{~m})$ for $4 \mathrm{~V}$ Secondary Lithium Cells. J. Electrochem. Soc. 1993, 140 (7), 1862-1870.

(37) Chang, K.; Hallstedt, B.; Music, D. Thermodynamic Description of the $\mathrm{LiNiO} 2-\mathrm{NiO} 2$ Pseudo-Binary System and Extrapolation to the 
$\mathrm{Li}(\mathrm{Co}, \mathrm{Ni}) \mathrm{O} 2-(\mathrm{Co}, \mathrm{Ni}) \mathrm{O} 2$ System. CALPHAD: Comput. Coupling

Phase Diagrams Thermochem. 2012, 37 (0), 100-107.

(38) Li, J.; Downie, L. E.; Ma, L.; Qiu, W.; Dahn, J. R. Study of the Failure Mechanisms of $\mathrm{LiNi0} .8 \mathrm{Mn} 0.1 \mathrm{Co} 0.1 \mathrm{O} 2$ Cathode Material for Lithium Ion Batteries. J. Electrochem. Soc. 2015, 162 (7), A1401A1408.

(39) Li, J.; Shunmugasundaram, R.; Doig, R.; Dahn, J. R. In Situ Xray Diffraction Study of Layered $\mathrm{Li}-\mathrm{Ni}-\mathrm{Mn}-\mathrm{Co}$ Oxides: Effect of Particle Size and Structural Stability of Core-Shell Materials. Chem. Mater. 2016, 28 (1), 162-171.

(40) Xie, H.; Du, K.; Hu, G.; Peng, Z.; Cao, Y. The Role of Sodium in LiNi0.8Co0.15Al0.05O2 Cathode Material and Its Electrochemical Behaviors. J. Phys. Chem. C 2016, 120 (6), 3235-3241.

(41) Yang, J.; Xia, Y. Suppressing the Phase Transition of the Layered Ni-Rich Oxide Cathode during High-Voltage Cycling by Introducing Low-Content Li2MnO3. ACS Appl. Mater. Interfaces 2016, 8 (2), $1297-1308$.

(42) Dokko, K.; Nishizawa, M.; Horikoshi, S.; Itoh, T.; Mohamedi, M.; Uchida, I. In Situ Observation of LiNiO2 Single-Particle Fracture during Li-Ion Extraction and Insertion. Electrochem. Solid-State Lett. 2000, 3 (3), 125-127.

(43) Nakai, I.; Takahashi, K.; Shiraishi, Y.; Nakagome, T.; Izumi, F.; Ishii, Y.; Nishikawa, F.; Konishi, T. X-ray Absorption Fine Structure and Neutron Diffraction Analyses of De-Intercalation Behavior in the $\mathrm{LiCoO} 2$ and LiNiO2 Systems. J. Power Sources 1997, 68 (2), 536-539.

(44) Nakai, I.; Takahashi, K.; Shiraishi, Y.; Nakagome, T.; Nishikawa, F. Study of the Jahn-Teller Distortion in LiNiO2, a Cathode Material in a Rechargeable Lithium Battery, by In Situ X-ray Absorption Fine Structure Analysis. J. Solid State Chem. 1998, 140 (1), 145-148.

(45) Mansour, A. N.; Yang, X. Q.; Sun, X.; McBreen, J.; Croguennec, L.; Delmas, C. In Situ X-ray Absorption Spectroscopy Study of Li(1z) $\mathrm{Ni}(1+\mathrm{z}) \mathrm{O} 2(z \leq 0.02)$ Cathode Material. J. Electrochem. Soc. 2000, 147 (6), 2104-2109.

(46) Mansour, A. N.; McBreen, J.; Melendres, C. A. An In Situ X-ray Absorption Spectroscopic Study of Charged $\mathrm{Li}((1-\mathrm{z})) \mathrm{Ni}((1+\mathrm{z})) \mathrm{O} 2$

Cathode Material. J. Electrochem. Soc. 1999, 146 (8), 2799-2809.

(47) Xu, J.; Lin, F.; Nordlund, D.; Crumlin, E. J.; Wang, F.; Bai, J.; Doeff, M. M.; Tong, W. Elucidation of the Surface Characteristics and Electrochemistry of High-Performance LiNiO2. Chem. Commun. 2016, 52 (22), 4239-4242.

(48) Li, W.; Reimers, J. N.; Dahn, J. R. In Situ X-ray Diffraction and Electrochemical Studies of Li1-xNiO2. Solid State Ionics 1993, 67 (12), 123-130.

(49) Balasubramanian, M.; Sun, X.; Yang, X. Q.; McBreen, J. In Situ X-ray Absorption Studies of a High-Rate $\mathrm{LiNi0} 85 \mathrm{Co} 0.15 \mathrm{O} 2$ Cathode Material. J. Electrochem. Soc. 2000, 147 (8), 2903-2909.

(50) Balasubramanian, M.; Sun, X.; Yang, X. Q.; McBreen, J. In Situ $\mathrm{X}$-ray Diffraction and X-ray Absorption Studies of High-Rate LithiumIon Batteries. J. Power Sources 2001, 92 (1-2), 1-8. 